\section{ON PERIODICITY OF GOOD AND BAD}

\section{$S E A S O N S .1$}

FEEL some reluctance in coming forward to-night, with the result of my investigations into the periodicity of good and bad seasons-floods and droughts if you will-because they must come to you as a surprise, and they will make a claim on your confidence which at first sight you will probably not be disposed to grant. For myself I know that some years ago, if any one had come to me stating that it was possible to forecast the seasons many years in advance, I should have received the statement with incredulity. The difficulty in getting the facts together is very great. I have had to ask from history records of passing phenomena which it has been the habit of the historian to neglect ; however, there will be before you a mass of evidence in support of my proposition, that there is a periodicity in weather. The weak point in the evidence is that history has not kept a regular and continuous account of droughts, but only recorded them when they became very prominent. The strong point is that all the data that history does give us is in favour of the nineteen years' cycle.

And it may be explained that the word drought is not used here in the sense in which it is often used in England and elsewhere, that is, to signify a period of a few days or weeks in which not a drop of rain falls ; but it is used to signify a period of months or years during which little rain falls, and the country gets burnt up, grass and water disappear, crops become worthless, and sheep and cattle die.

Drought is, however, not wholly made by a deficiency of rainfall. Its most important factors are great heat and drying winds. As an illustration we may look to the year 1895 ; in the latter part of winter and in spring there were many falls of rain, which would have made grass in ordinary seasons, although there was not as much as usual, but it had no sooner fallen than a dry north-west wind and burning sun dried it all up. This great and burning heat was a well-known feature in historical droughts, and some authorities say that the fable of Phaëton driving the chariot of the Sun so close to the earth that he set it on fire, is a poetical setting of an actual experience in Greece when the sun became so powerful that the heat was almost beyond endurance.

Before 1895 all the diagrams I used had been made to show quantities of the various elements, and their relation in time, with a view to seeing if there was any periodicity. Recently it occurred to me that it would be useful to have a diagram in which all the dronghts, without regard to their intensity, should be placed in their order of time; not only was this desirable for seeing what the relation in time was, but it had become evident that it would be impossible to see the relation between our droughts and those in other countries, unless some such pictorial arrangement was made.

As a preliminary to making the diagram, the particulars of the weather in this colony from all sources, for every year of our history, were carefully examined, and the years simply classed as good or bad ; that is, having sufficient or insufficient rainfall. A form was then prepared with a vertical space for each year, and across these a zero line was drawn to divide the good from the bad; and, beginning with I 895 , I filled in for that year, and below the line, a convenient length of the column in red ink; the length was simply to catch the eye. Then for I894, a good year, I filled in with black ink, above the line, a space equal to the red in the vertical space for 1894 . The two years were thus contrasted simply as good and bad; the question of how good, or how bad, was purposely left out. The diagram was then c)mpleted, each year being treated in the same way back to 1788. It was at once apparent that a drought lasting from three to seven years was most regular in its occurrence. A vertical red line.was then drawn between the first and second years of each of these dry periods, and it was found that the interval between two successive lines was regular and exactly nineteen years. The centres of another set of dry periods, more intense and relatively shorter than the first series, were found also to recur at intervals of nineteen years. One of these droughts falls regularly between a pair of the more extensive droughts previously referred to.

In the whole period, from the foundation of the colony of New South Wales to the present year, i.e. 108 years, it is certainly very noteworthy that the most pronounced droughts

1 Abridged from a paper read before the Royal Society of New South Wales, June 3 , by H. C. Russell, C.M.G., F.R.S.

NO. I 399, VOL. 54] recur with great regularity-that is, at every nineteen years throughout the 108 years. Indian droughts seem to have coincided with Australian ones in many instances.

The investigation had become interesting, and seemed to promise to show the exact year of the great drought in this country, of which there was abundant evidence when the colonists landed here, both in the fact that to the south of Sydney all the very large trees were dead, and between them were growing young trees; and the story of the blacks, who said that the river Hunter dried up; that all the great trees died, and most of the blacks; that those who survived had obtained drinking-water from the mountain springs. I had long wanted to find out when this terrible drought in this colony took place, and the Indian record showed that the extensive drought had been repeated in $1769-70$, which probably fixes the date; for the middle of the eighteenth century was very dry, generally, all over the world.

But, if we can carry the nineteen years' period in this way back beyond our history, the idea immediately presents itself, where are you going to draw the limit, is there any limit? It was evidently not a question for argument, but for proof or disproof by figures. Tables were prepared showing every date on which droughts of the first class recurred back to A.D. I, and the same for droughts of the second class. I am not going to weary you by going through the list, but will give you the result. History says very little about droughts prior to A.D. 900 . Between that date and this, a drought has, on the assumption, occurred at every nineteen years. In this interval of nine hundred and ninety. six years there have been fifty-two repetitions of drought, and the question is what has history to say about its droughts. Well, it shows that these droughts have been repeated at various places on the earth on forty-four of the fifty-two dates; of these eight missing droughts, no less than six of them occurred between rooo and 900 A.D., an interval when history was less complete on these matters. So far as I have gone, history furnishes us with seventyeight droughts in different couritries, all of which fit into the first series. During the same period, droughts of the second series recurred fifty-one times, and history records droughts, numbering eighty-nine, on thirty-six of these periods. Taking then the droughts history has recorded between A.D. 900 and 1896, we have seventy-eight of the first series and eighty-nine of the second, a total of one hundred and sixty-seven, out of two hundred and eight on record; but this is not all, for another class of drought, which is irregular in Australia, seems to be more definite and important in the northern hemisphere, and twenty. six more out of the two hundred and eight belong to this series, making up the number to one hundred and ninety-three out of the total of two hundred and eight.

In estimating the importance of these figures, it must be remembered that, before 1788 , North and South America, Russia China, Persia, Turkey, Austria and Australia, all subject to frequent drought, yet did not, however, furnish to the numbers quoted more than you could count on your fingers ; and it may be fairly assumed that if we had these records, and especially if history had made a point of recording droughts, we should have had drought recorded on every recurrence of the nineteen years' cycle, of the two chief series; but I think the evidence that history furnishes one hundred and ninety-three recorded droughts, every one of which fits into the cycle, justifies us in assuming that the nineteen years' cycle has been running for at least one thousand years, and may be trusted to continue and justify forecasts based upon it for some time to come.

Having got so much from the study of droughts in the Christian era, it seemed desirable to see if there were any recorded in B.c. times. Records of twenty B.C. droughts were found, all of which, with one exception, fit into our nineteen years' cycle. If these dates are examined apart from their connection with Australian droughts, we find that the intervals between them are multiples of nineteen years, which shows that droughts then, as now, occurred in cycles of nineteen years, which is very strong evidence in favour of our theory, the more so when it is remembered that all the B.C. droughts I have been able to collect, except one, do fit in : they do not form a series of droughts selected for the purpose of supporting it; again, taking the dates given in the various works, the intervals between all these B.c. droughts and those in Australia are multiples of nineteen years.

If it be objected that chronologists have grave doubts about the accuracy of b.C. dates, I reply, that it is quite certain that chronologists did not arrange the dates to make them fit into an 
unknown cycle running amongst these droughts, or in connection with Australian droughts, the dates of which have been unknown until now. These dates are points in history, and the fact that they fall into a cycle of weather, itself supported by all the available drought dates of the last thousand years of history, is in strong confirmation of the accuracy of these B.c. dates.

These intervals in which ourdroughts are found repeated are surprising, but I am not unaware of the differences of opinion in regard to chronology, but take the dates as given, and it is remarkable how exactly they fit in. But there is another point of importance hidden in these dates, and probably you have not noticed it. Pharaoh's drought was predicted, and a Jew was made chief man under the king, and he was doubtless versed in much of the wisdom of the priests, and carried that wisdom to the Jewish priests, who did not forget it, as the figures make manifest, and if warning of such evils could be repended upon, it is not likely they would forget it. The figures show that Elijah's prediction was a repetition of Pharaoh's drought $42 \times 19$ years after it; also Elisha's prediction was nineteen years after Elijah's, and it is noteworthy that the drought in David's time, although it does not appear to have been predicted, was $19 \times 36$ after Pharaoh's, This seems to me to be very strong evidence in favour of the view that the Egyptians knew of the nineteen years' cycle, and that the Jews brought the knowledge away with them.

Those learned in Assyrian antiquities tell us that the book containing "the Observations of Bel," the oldest astronomical book of that part of the world, was ordered to be kept by the king 3800 years B.C. ; that book shows that they kept a record of astronomical and all other events, that they had discovered the nineteen years' cycle of eclipses, and we are told that it was a doctrine with them, that one event caused another, and all astronomical and meteorological observations were thus bound up together. Under such conditions I do not think it would be possible for them to avoid finding in the droughts a similar period to that in the eclipses, i.e. nineteen years; but even if they did, it would have been impossible for those who kept the Nilometer in Egypt to avoid finding it in the heights of the Nile floods, which were of such vital importance and so carefully recorded.

Since I have been working at this subject there have been a number of red rain storms noted in New South Wales, and the latest, on April Io, suggested to me this line of investigation. Red dust is obviously a proof of drought somewhere, otherwise the dust could not rise ; and since these proofs of drought are entirely apart from the others, and recorded not as droughts but as marvels, which in days gone by created no little alarm, it will be worth while to see how far they support or contradict the nineteen years' cycle. The result of this resolution came as a surprise to me, because it was so unexpected; I had no idea there were so many records of red rains, or that they went so far back in history.

There are altogether sixty-nine recorded instances of the fall of red rain; of these I have recorded six for New South Wales. The first was fourteen years after the foundation of the city of Rome, that is in B.C. 738 , and there are nine others B.C., all of which fit into the nineteen years' cycle; between 538 B.C. to 582 A.D. I can find no record of red rain, but from 582 to 1896 there are fifty-nine recorded falls of red rain, and all of them fit into the nineteen years' cycle. We have here, then, ten B.C. droughts which go with the eight mentioned before to make eighteen B.C. droughts in support of the cycle, the remainder, fifty-nine, are included in the previous list.

I have endeavoured to put before you some of the reasons which have convinced me that there is a cycle in weather; but the necessity for brevity in order to keep within the limits of one address, has rendered it necessary to express in a few sentences the results of many separate investigations, and the evidence does not seem so strong when thus condensed as it does when a number of facts one by one are brought to light from diverse sources, all of which individually support the proposition. I can assure you that the evidence was far more convincing when taken in detail ; but want of time to get these details into one address, make this course impossible. Enough appears to have been said to prove that the cycle does exist, and to show the very great importance of this re-discovery of a law of climate which. there are many reasons to think, was well known to the Jews, the Egyptians, and other ancient peoples; they at least knew how to forecast droughts success- fully, and in Egypt, like sensible people, made provisions for them.

An examination of the weather of one hundred years of New South Wales has shown that certain features recur every nineteen years; we have seen that the droughts of history-the great and conspicuous droughts I mean-all drop into this same cycle: both those that happened before the birth of Christ, and those that have occurred in our era ; for instance, Elijah's drought happened in B.C. 908 , that is, 2736 before our great drought in I 828 , and the interval is $19 \times 144$. Great hurricanes, the great frosts of history, all the red rains, and all the dronghts that history records, with a very few exceptions, likewise are included in this cycle, and the level of great lakes in Palestine, South America, and New South Wales are subject to the same mysterious influence that controls our weather.

As my investigation proceeded, the weight of evidence gradually converged upon the moon as the exciting cause. I have never had any sympathy with the theory of lunar influence upon weather, and received, rather against my will, the evidence that presented itself; still the logic of facts left no alterrative but to accept the moon as prime motor. There has not been time to complete this investigation, and when finished it must form another paper. Meantime I may say that, so far, the comparison of the moon's positions in relation to the sun and earth and droughts shows that when the eclipses congregate about the equinoxes, that is, in March and September, they do so in the years which give us great droughts. Further, that when the eclipses accumulate in February and March, that is, at the vernal equinox and the month before it, and September, the autumnal equinox, and the month before it, August, we have the more intense and relatively shorter droughts of the second series, with heat, gales and hurricanes; on the other hand, when they accumulate about March and April, that is, the month of equinox, and the one following, and about September, the month of equinox, and October following it, we have droughts of the first series that are less severe, but much longer than the droughts of the second series. I have spoken chiefly of droughts; though, so far as our own history is concerned, it would have served the purpose just as well if I had taken up the periodicity of wet years, but outside Australia it would have been very difficult to get the necessary data, for history has much more to say about the horrors os drought than the abundance of wet seasons.

\section{SNAKE VENOM AND ANTI-VENOMOUS SERUM.}

I HAVE already recorded in a series of memoirs published since 1892 in the Annales de l'Institut Pasteur and in the Comptes rendus de l'Acadimie des Sciences, the results of my researches on the venom of snakes, on the immunisation of animals against this venom, and upon the production of an antivenomous serum. Prof. Fraser has confirmed the facts that I have published, and has successfully repeated almost all my experiments. I bring before you, to-day, a series of new facts relative to the same question. I may say at the outset, in contradiction of the opinion recently expressed by certain physio. logists, that it is fully proved that the venoms of the various species of snakes produce physiological phenomena which have certain features common to all, and that the actions of these venoms only differ as regards their local effects. It is now possible to separate, artificially, the substances which produce the local phenomena from those which produce the bulbar intoxication. This separation may be effected by means of heat. If any sample of venom be thrown into watery solwtion and heated at $85^{\circ} \mathrm{C}$. for a period of fifteen minutes, the albumin contained in the solution is coagulated and the phlogogenic substances are destroyed, whilst the toxicity of the substance is entirely unaffected. MM. Phisalix and Bertrand have already demonstrated this fact in the case of the venom of the viper found in France. After heating at $85^{\circ} \mathrm{C}$. and filtration, al venoms, both viperine and colubrine, produce the same effects; they only differ as to the degree of their toxic activities. Similarly all are destroyed by the hypochlorites of the alkalis and by chloride of gold, the use of which substances I have suggested-particularly the hypochlorite of lime in a solution of

1 Abridged from a paper read before the Section of Pathology and Bacteriology of the British Medical Association, by Prof. A. Calmette, Director of the Pasteur Institute, Lille.

NO. I 399, VOL. 54] 